\title{
Multilateral subsidy games
}

\author{
Dermot Leahy $\cdot$ J. Peter Neary
}

Received: 5 September 2007 / Accepted: 20 May 2008 / Published online: 10 June 2008 (C) The Author(s) 2008

\begin{abstract}
This paper examines the rationale for multilateral agreements to limit investment subsidies. The welfare ranking of symmetric multilateral subsidy games is shown to depend on whether or not investment levels are "friendly", raising rival profits in total, and/or strategic complements, raising rival profits at the margin. In both Cournot and Bertrand competition, when spillovers are low and competition is intense (because goods are close substitutes), national-welfare-maximizing governments oversubsidize investment, and banning subsidies would improve welfare. When spillovers are high, national governments under-subsidize from a global welfare perspective, but the subsidy game is welfare superior to non-intervention.
\end{abstract}

Keywords Industrial policy $\cdot$ Investment subsidies $\cdot$ Subsidy wars ·

Strategic trade policy $\cdot$ R\&D spillovers $\cdot$ Oligopoly

JEL Classification $\quad \mathrm{L} 13 \cdot \mathrm{F} 12$

For helpful comments we are grateful to two referees, to Arijit Mukherjee, and to participants in seminars at Prague and UCD, at the EEA Conference in Lausanne and at the GEP Conference on "New Directions in International Trade Theory" at the University of Nottingham, June 2007. Dermot Leahy acknowledges the support of the Science Foundation Ireland Research Frontiers Programme (Grant MAT 017).

D. Leahy

Department of Economics, National University of Ireland, Maynooth,

Maynooth, Kildare, Ireland

e-mail: dermot.leahy@nuim.ie

J. P. Neary (西)

Department of Economics, University of Oxford,

Manor Road Building, Oxford OX1 3UQ, UK

e-mail: peter.neary@economics.ox.ac.uk 


\section{Introduction}

National governments often subsidize the investment undertaken by domestic firms that compete on international markets. While there is now a substantial literature concerned with nationally optimal policy towards investment in both open and closed economies, the effects of such policies on countries' trading partners have received much less attention. This is surprising for at least two reasons. On the one hand, investment subsidies can be used as a strategic trade policy instrument and so might be expected to have a beggar-thy-neighbour aspect. On the other hand, when the investment is in R\&D, it typically generates spillovers that can benefit firms in other countries. As a result, $R \& D$ subsidies may be expected to increase the positive externality. In this paper we are concerned with how the welfare of a group of countries is affected by national subsidies to investment, whether in the form of capital, capacity or R\&D. In particular we ask whether there is a case for limiting such subsidies.

These issues are timely since there is a growing policy consensus that direct state aid in the form of production or export subsidies is undesirable, but that investment subsidies are much more benign. In the European Union, for example moves are under way to change the balance of assistance. In a 2005 consultation document on reform of state aid by European governments, sub-titled Less and Better Targeted State Aid, the European Commission proposes a shift away from subsidies to production or fixed costs towards more targeted assistance, with a particular emphasis on R\&D subsidies. $^{1}$

The pros and cons of investment subsidies are related to but distinct from those of export or production subsidies. It is now well understood that in oligopolistic markets national governments may face unilateral incentives to subsidize exports or production, and that such subsidization typically leads to a prisoner's dilemma, where each country would gain if their policy independence were curtailed. ${ }^{2}$ However, as is also well-known, the prediction that national governments will want to offer export or production subsidies is not very robust. By contrast, the literature on strategic trade and industrial policy has shown that the case for investment subsidies is much more robust, from the perspective of an individual country. When an export subsidy is unavailable, an investment subsidy is typically nationally optimal when a domestic oligopolist faces foreign rivals, and industrial policy can be used by a national government to help its firm capture a larger share of the rents in imperfectly competitive markets. This has been shown by Spencer and Brander (1983), Bagwell and Staiger (1994), Maggi (1996), and Neary and Leahy (2000) in a variety of special models, while Leahy and Neary (2001) show that the result is

\footnotetext{
1 See Commission of the European Communities (2005). The ongoing debate at European level is documented at http://ec.europa.eu/comm/competition/state_aid/reform/reform.html.

2 Brander and Spencer (1985) is a classic early statement of this result. Extensions and explorations of the robustness of the result have generated a large literature which is reviewed in Brander (1995).
} 
robust for a wide class of models. ${ }^{3}$ An export subsidy would be a more direct way to capture market share and when it is also available it takes over the rent-shifting role. However, direct export subsidies are banned under the WTO, though persisting in more surreptitious forms, whereas no similar ban applies to investment subsidies.

Given that all governments have an incentive to use rent-shifting investment subsidies, such subsidy wars among exporters can result in a prisoner's dilemma. In that case, all the exporting countries would be better off if they agreed to ban investment subsidies outright. However, from a global first-best perspective that includes the welfare of consumers, the oligopolistic distortion implies that output is below the Pareto efficient level. Higher output due to subsidization would be beneficial in that it would help to undo this oligopoly distortion. Another type of distortion arises because, when firms compete strategically, investment is not chosen at the socially efficient level. Whether the industrial policy chosen by national governments helps to mitigate or exacerbate this particular distortion depends to a great extent on the level of spillovers. Thus the welfare effects of international industrial policy games for a group of countries or for the world as a whole are quite complex and justify careful analysis.

We consider three different policy regimes in this paper. Our main concern is to compare the regime in which governments use investment subsidies to that in which they do not intervene. In particular, we ask whether the welfare of the group of countries would be improved if they committed to ban subsidies altogether. To answer the latter question we compare union welfare in the investment subsidy game to that in the nonintervention regime. Given the subsidies chosen by its trading partners, a government restricted to using an investment subsidy can only attain the "National Second Best".

If subsidies to production as well as investment were permitted, then a natural benchmark against which to compare the investment subsidy and laissez-faire regimes would be the "Global First Best," in which investment is chosen at the efficient level and price is set equal to marginal cost. However, as already noted, direct production subsidies are typically banned by international agreements. An alternative and more plausible benchmark is the "cooperative" optimum defined as the highest joint welfare that can be obtained without a production subsidy. This would be attained if the national governments were to cooperate in subordinating their policy discretion to a supra-national body (such as the European Commission). It represents a second-best for the group of countries, subject to the constraint that the product-market distortions cannot be offset directly by subsidies.

The issue of state aid to industry by a group of countries has been considered in relatively few papers. Besley and Seabright (1999) argue that all such aids are

\footnotetext{
3 Spencer and Brander (1983) were the first to consider this issue, in a model where firms first invest in R\&D and than engage in Cournot competition. Bagwell and Staiger (1994) considered the case of Bertrand competition with linear demands. Maggi (1996) considered an extension of the model of Kreps and Scheinkman (1983) in which second-period competition is in prices, but the outcome of the full game may resemble that of either a Cournot or a Bertrand one-period game depending on the value of a cost parameter which represents the cost penalty of producing above capacity. He showed that the optimal investment subsidy is positive irrespective of the value of the cost parameter. Neary and Leahy (2000) provide a general framework for this literature, stressing the second-best nature of the case where an export subsidy is unavailable.
} 
welfare-reducing, but Collie (2000, 2002) notes that they may serve to offset oligopolistic under-production in the absence of an active multilateral anti-trust policy. He considers a model of an economic union, and provides an explanation for the desire of individual national governments to give unilateral production subsidies and the desire of the supra-national union authority to limit them. Collie (2005) and Haaland and Kind $(2006,2008)$ consider similar issues in the context of R\&D subsidies, though only in relatively special models. ${ }^{4}$ In this paper we seek to compare the welfare effects of different policies in a general model which encompasses most of those in the literature. Our framework can be thought of as a multilateral generalization of Neary and Leahy (2000). That paper considered the case in which only the home government is policy active and did not provide general welfare conclusions. It is only possible to compare such asymmetric equilibria when special functional forms are imposed. By focusing instead on symmetric equilibria we are able to generalize greatly in other directions, allowing general functional forms and also encompassing both quantity and price competition.

The plan of the paper is as follows. The general multi-country multi-firm model is presented in Sect. 2 and government behaviour is introduced in Sect. 3. Sections 4 and 5 derive the main results for the cases where the welfare weight attached to domestic consumption is zero or positive respectively. Section 6 considers in more detail the linear-quadratic special case with Cournot competition, and Sect. 7 shows that similar results hold under Bertrand competition. Finally, Sect. 8 concludes with a summary of results.

\section{Firm behaviour}

We consider a symmetric oligopolistic industry with $n$ identical firms, each of which is located in one of $n$ countries, and sells on a single integrated market with no tariffs or transport costs. The game proceeds in three stages. In the first stage, subsidies are set either by national governments or by a supra-national authority, in a manner to be considered in later sections. In the remaining stages, the firms compete simultaneously. In the second stage each firm chooses its investment expenditure $k^{i}$, and in the third stage it chooses a market action $A^{i}$, which may be either output $x^{i}$ or price $p^{i}$.

Each firm's total profits, denoted by $\Pi^{i}$, consists of its operating profits, $\pi^{i}$, less investment costs $\Gamma$, plus investment subsidy revenue $s^{i} k^{i}$. Operating profits in turn equal sales revenue less production costs, but we do not need to make these components explicit in the general model. Hence profits can be written as follows:

$$
\Pi^{i}\left(\mathbf{k}, \mathbf{A}, s^{i}\right) \equiv \pi^{i}(\mathbf{k}, \mathbf{A})-\Gamma\left(k^{i}\right)+s^{i} k^{i}
$$

\footnotetext{
4 Collie $(2000,2002)$ consider production subsidies only, the former in a model of homogeneous product Cournot competition with general demands, the latter in both Cournot and Bertrand competition with differentiated goods and linear demands. Collie (2005) considers R\&D subsidies in a model of Cournot competition with linear demands. Haaland and Kind (2006, 2008), written independently of this paper, also consider R\&D subsidies, assuming Cournot duopoly, linear demands, and differentiated products.
} 
where $\mathbf{k}=\left[k^{1} \ldots k^{i} \ldots k^{n}\right]^{\prime}$ is the vector of all firms' investment levels and $\mathbf{A}=\left[A^{1} \ldots A^{i} \ldots A^{n}\right]^{\prime}$ is the vector of all firms' market actions. This specification of the profit function is extremely general. The investment carried out by a firm could be in capital or in process $R \& D$, in which case it leads to a reduction in its own production costs. It could also be in marketing or product quality, which shifts outwards the demand function it faces. In addition, if the investment is in R\&D or in marketing, it may have spillover effects on the profits of other firms. As for the final stage, competition may be either Cournot or Bertrand.

As is natural in these models, we confine attention to subgame-perfect equilibria, and so the model must be solved backwards. The third-stage first-order condition for a typical firm is:

$$
\frac{\partial \pi^{i}(\mathbf{k}, \mathbf{A})}{\partial A^{i}}=0
$$

We assume that there is a unique equilibrium of the third-stage game. Hence these first-order conditions for all $n$ firms can be combined and solved to give the market actions as a function of the investment levels: $\mathbf{A}(\mathbf{k})$.

In the second stage, each firm chooses its optimal level of investment anticipating the effects of its choice on the third-stage actions. To account for this, it proves very convenient to introduce a reduced form operating profit function, which depends directly only on investment levels as follows:

$$
\hat{\pi}^{i}(\mathbf{k}) \equiv \pi^{i}[\mathbf{k}, \mathbf{A}(\mathbf{k})]
$$

Similarly we can write a reduced-form function for total profits:

$$
\hat{\Pi}^{i}\left(\mathbf{k}, s^{i}\right) \equiv \hat{\pi}^{i}(\mathbf{k})-\Gamma\left(k^{i}\right)+s^{i} k^{i}
$$

Hence the firm's optimal choice of investment in the second stage implies the following condition:

$$
\frac{\partial \hat{\Pi}^{i}}{\partial k^{i}}=\hat{\pi}_{i}^{i}-\Gamma^{\prime}+s^{i}=\mu \theta x^{i}-\Gamma^{\prime}+s^{i}=0
$$

This shows that firms will invest up to the point where the marginal return $\hat{\pi}_{i}^{i}$ equals the net marginal cost of investment $\Gamma^{\prime}-s^{i}$. For later use, it is convenient to write this marginal return in terms of two parameters (not necessarily constant of course), $\theta$ and $\mu$, defined implicitly as follows:

$$
\theta x^{i}=\frac{\partial \pi^{i}}{\partial k^{i}} \quad \text { and } \quad \mu \theta x^{i}=\hat{\pi}_{i}^{i}=\frac{\partial \pi^{i}}{\partial k^{i}}+\sum_{j=1}^{n} \frac{\partial \pi^{i}}{\partial A^{j}} \frac{\mathrm{d} A^{j}}{\mathrm{~d} k^{i}}
$$

Here $\theta$ is the marginal return to investment per unit output $x^{i}$ at given values of $\mathbf{A}$, while $\mu$ is one plus the strategic component of the marginal return to investment when 
firms anticipate the effects of their actions on rivals' $A^{j}$; hence $\mu$ is the ratio of the full effect to the partial effect: $\mu=\hat{\pi}_{i}^{i} / \frac{\partial \pi^{i}}{\partial k^{i}}$. A value for $\mu$ of unity is the non-strategic benchmark, so, following Fudenberg and Tirole (1984), we can say that firms engage in strategic over-investment when $\mu$ is greater than one, and conversely.

\section{Global and national welfare}

Consider next the choice of investment subsidy in the first stage of the game. This raises two issues: the specification of national welfare and the nature of the policy regime. We consider these in turn.

We assume that national welfare is a weighted sum of domestic consumer surplus and profits net of subsidy payments:

$$
W^{i}(\mathbf{k}, \mathbf{A}) \equiv \delta B^{i}(\mathbf{k}, \mathbf{A})+\Pi^{i}\left(\mathbf{k}, \mathbf{A}, s^{i}\right)-s^{i} k^{i}
$$

where $\delta$ is the weight attached to consumer surplus $B^{i}$. A value of $\delta$ equal to zero corresponds to either the case where all output from home firms is exported outside the union; or the case where there is some domestic consumption but governments attach no value to it because they have been fully captured by producer interests. Note also that we write consumer surplus as a function of $\mathbf{k}$ as well as of $\mathbf{A}$, since this allows for a direct effect of investment on consumer welfare, for example through expenditure on marketing or quality improvement. Making use of (1) to eliminate total profits from (7) yields:

$$
W^{i}(\mathbf{k}, \mathbf{A})=\delta B^{i}(\mathbf{k}, \mathbf{A})+\pi^{i}(\mathbf{k}, \mathbf{A})-\Gamma\left(k^{i}\right)
$$

so welfare depends directly only on $\mathbf{k}$ and $\mathbf{A}$, since it is independent of the subsidy.

Turning to our assumptions about policy, we consider three different regimes, which we call Laissez-Faire $(L)$, Non-Cooperative Intervention $(N)$ and Cooperative Intervention $(C)$, respectively. The laissez-faire equilibrium arises when all subsidies $s^{i}$ are zero, and can be thought of as arising from a commitment to non-intervention on the part of the $n$ countries' governments. In the non-cooperative intervention case, countries play a Nash game in subsidies, each seeking to maximize national welfare as given by (8). Finally, the cooperative equilibrium occurs when a supra-national authority chooses a uniform subsidy to maximize the countries' aggregate welfare, which is simply the sum of their individual welfare levels:

$$
W(\mathbf{k}, \mathbf{A})=\sum_{i}^{n} W^{i}(\mathbf{k}, \mathbf{A})
$$

The equilibrium in the laissez-faire regime is given by the first-order conditions for investment in (5) for all firms, with the subsidies $s^{i}$ equal to zero. In particular, it can be characterized by a value for the marginal return to investment equal to $\mu \theta$. To 
derive the equilibria in the two policy-active regimes we must turn next to the optimal choice of subsidies.

\section{Non-cooperative and cooperative profit-shifting}

We begin by focusing in this section on the pure profit-shifting case where consumption of the good is not valued, so $\delta=0$. Given this, we need to consider separately the cases of non-cooperative and cooperative intervention.

In the non-cooperative case, the government of country $i$ chooses its subsidy to maximize its own welfare only. Anticipating the choice of investment levels and market actions by all firms in the second and third stages, it therefore seeks to maximize a reduced-form welfare function, analogous to the reduced-form profit function (4):

$$
\hat{W}^{i}(\mathbf{k}) \equiv W^{i}[\mathbf{k}, \mathbf{A}(\mathbf{k})]
$$

In setting its optimal subsidy $s^{i}$, the government of country $i$ anticipates its effects on the investment levels of all firms:

$$
\frac{\mathrm{d} \hat{W}^{i}}{\mathrm{~d} s^{i}}=\sum_{j=1}^{n} \frac{\partial \hat{W}^{i}}{\partial k^{j}} \frac{\mathrm{d} k^{j}}{\mathrm{~d} s^{i}}=0
$$

However, from (5), the second-stage reaction functions of other firms $(j \neq i)$ and hence their investment levels do not depend directly on $s^{i}$; rather they depend on $s^{i}$ only indirectly through their dependence on $k^{i}$ :

$$
\frac{\mathrm{d} k^{j}}{\mathrm{~d} s^{i}}=\frac{\mathrm{d} k^{j}}{\mathrm{~d} k^{i}} \frac{\mathrm{d} k^{i}}{\mathrm{~d} s^{i}}, \quad j \neq i
$$

Hence the first-order condition for optimal choice of subsidy by government $i$ can be written as:

$$
\frac{\mathrm{d} \hat{W}^{i}}{\mathrm{~d} s^{i}}=\frac{\mathrm{d} \hat{W}^{i}}{\mathrm{~d} k^{i}} \frac{\mathrm{d} k^{i}}{\mathrm{~d} s^{i}} \quad \text { where: } \quad \frac{\mathrm{d} \hat{W}^{i}}{\mathrm{~d} k^{i}}=\sum_{j=1}^{n} \frac{\partial \hat{W}^{i}}{\partial k^{j}} \frac{\mathrm{d} k^{j}}{\mathrm{~d} k^{i}}
$$

Ruling out the degenerate case where $\frac{\mathrm{d} k^{i}}{\mathrm{~d} s^{i}}$ is zero, this implies that at the optimum we must have $\mathrm{d} \hat{W}^{i} / \mathrm{d} k^{i}=0$. This yields the following condition for optimal choice of investment:

$$
\begin{gathered}
\frac{\mathrm{d} \hat{W}^{i}}{\mathrm{~d} k^{i}}=\mu_{N} \theta x^{i}-\Gamma^{\prime}=0 \\
\text { where: } \mu_{N} \theta x^{i}=\hat{\pi}_{i}^{i}+(n-1) \hat{\pi}_{j}^{i} \frac{\mathrm{d} k^{j}}{\mathrm{~d} k^{i}}
\end{gathered}
$$

Here $\mu_{N}$ denotes the strategic component of the marginal return to investment per unit output, when subsidies are chosen non-cooperatively to maximize national welfare. 
By contrast, in the cooperative case, the supra-national authority chooses all subsidies simultaneously to maximize total profits net of subsidies, $\hat{W}(\mathbf{k})=\Sigma_{i} \hat{W}^{i}(\mathbf{k})$, taking account of the effects of each subsidy on the investment levels of all firms:

$$
\frac{\mathrm{d} \hat{W}}{\mathrm{~d} s^{i}}=\sum_{j} \frac{\partial \hat{W}}{\partial k^{j}} \frac{\mathrm{d} k^{j}}{\mathrm{~d} s^{i}}=0 \quad \forall i
$$

Once again, we rule out the degenerate case where any of the $\mathrm{d} k^{j} / \mathrm{d} s^{i}$ is zero. Hence optimal choice of subsidies implies $\partial \hat{W} / \partial k^{j}=0$ for all $j$ (or, equivalently, $\partial \hat{W} / \partial k^{i}=$ 0 for all $i$ ). This yields a different condition for optimal choice of investment by firm $i$ :

where:

$$
\begin{aligned}
\frac{\partial \hat{W}}{\partial k^{i}} & =\mu_{C} \theta x^{i}-\Gamma^{\prime}=0 \\
\mu_{C} \theta x^{i} & =\hat{\pi}_{i}^{i}+(n-1) \hat{\pi}_{i}^{j}
\end{aligned}
$$

Once again, we use $\mu_{C}$ to denote the strategic component of the marginal return to investment per unit output, when subsidies are chosen cooperatively to maximize union welfare.

Having derived three expressions for the marginal return to investment, $\mu, \mu_{N}$ and $\mu_{C}$, corresponding to each of the three regimes, $L, N$ and $C$, we can now compare them explicitly. In doing so, we need to keep in mind that these marginal returns are derived from three different sets of first-order conditions corresponding to three different assumptions about government behaviour. Hence in equilibrium they are evaluated at different values of $\mathbf{k}$. Fortunately, we can nevertheless derive a number of results, first by making pairwise local comparisons between the marginal returns at a common point, and later by extending these to global comparisons by adapting techniques developed in Leahy and Neary (1997).

Consider first the choice between non-intervention and non-cooperative subsidy setting. Combining the expressions for $\mu$ and $\mu_{N}$ from Eqs. (6) and (14), both evaluated at the noncooperative equilibrium, we can derive the following expression for the difference between $\mu_{N}$ and $\mu$, which is proportional to the nationally optimal subsidy $s_{N}^{i}$ :

$$
\left(\mu_{N}-\mu\right) \theta x^{i}=s_{N}^{i}=(n-1) \hat{\pi}_{j}^{i} \frac{\mathrm{d} k^{j}}{\mathrm{~d} k^{i}}
$$

This is a generalization of the two-firm case considered in Leahy and Neary (2001), which draws on a result for the export subsidy game in Brander (1995). It shows that the sign of the difference between $\mu_{N}$ and $\mu$, and hence the sign of the nationally optimal subsidy, depends on the product of two terms. The first of these, $\hat{\pi}_{j}^{i}$, is the cross-effect of one firm's investment on another's profits, and we can say (following Brander) that it is positive if investment levels are "friendly"; while the second term, $\frac{\mathrm{d} k^{j}}{\mathrm{~d} k^{i}}$, is the effect of an increase in one firm's investment on another's optimal choice of investment. The sign of the latter depends on the cross-effect of one firm's investment on another's 
marginal profits, i.e. on whether investment levels are strategic substitutes $\left(\hat{\Pi}_{j i}<0\right)$ or strategic complements $\left(\hat{\Pi}_{j i}>0\right)$. This is shown by the following lemma: ${ }^{5}$

Lemma 1 An increase in one firm's investment raises a rival firm's optimal choice of investment if and only if investment levels are strategic complements.

Proof To determine the effect of a change in one firm's investment $k^{i}$ on a rival firm's investment $k^{j}$, we first totally differentiate the first-order condition for investment by firm $j$, Eq. (5), which can be written compactly as $\hat{\Pi}_{j}^{j}\left(\mathbf{k}, s^{j}\right)=0$. This gives:

$$
\hat{\Pi}_{j j} \mathrm{~d} k^{j}+\hat{\Pi}_{j i} \mathrm{~d} k^{i}+(n-2) \hat{\Pi}_{j h} \mathrm{~d} k^{h}=0
$$

Since $\mathrm{d} k^{h}=\mathrm{d} k^{j}$ and $\hat{\Pi}_{j h}=\hat{\Pi}_{j i}$ in symmetric equilibrium, this implies:

$$
\frac{\mathrm{d} k^{j}}{\mathrm{~d} k^{i}}=-\frac{\hat{\Pi}_{j i}}{\hat{\Pi}_{j j}+(n-2) \hat{\Pi}_{j i}}
$$

The denominator of this expression must be negative: this is obvious when $\hat{\Pi}_{j i}$ is negative, since $\hat{\Pi}_{j j}$ must also be negative from the firm's first-order condition; and when $\hat{\Pi}_{j i}$ is positive it is implied by the Seade necessary condition for stability: $\hat{\Pi}_{j j}+(n-1) \hat{\Pi}_{j i}<0$. (See Seade 1980.) Hence $\mathrm{d} k^{j} / \mathrm{d} k^{i}$ is positive if and only if the numerator is positive, i.e. if and only if investment levels are strategic complements $\left(\hat{\Pi}_{j i}>0\right)$.

Armed with this lemma, we can conclude that the return to investment in the noncooperative policy regime will be higher than in laissez-faire if and only if an increase in investment by one firm has the same qualitative effect on its rivals' profits in total and at the margin. Formally:

Proposition 1 When consumption is not valued $(\delta=0)$, the return to investment in the non-cooperative policy regime will be higher than in laissez-faire $\left(\mu_{N}>\mu\right)$, both evaluated at a common point, if and only if $\hat{\pi}_{j}^{i}$ and $\hat{\Pi}_{i j}$ have the same sign.

Next, we wish to compare $\mu_{C}$ and $\mu$. From (6) and (16), it is clear that the difference between them depends only on investment friendliness $\hat{\pi}_{j}^{i}$ :

$$
\left(\mu_{C}-\mu\right) \theta x^{i}=s_{C}=(n-1) \hat{\pi}_{j}^{i}
$$

Once again, provided this difference is evaluated at the cooperative equilibrium, it is proportional to the cooperative or multilaterally optimal subsidy $s_{C}$. Formally:

Proposition 2 When consumption is not valued $(\delta=0)$, the return to investment in the cooperative policy regime will be higher than in laissez-faire $\left(\mu_{C}>\mu\right)$, both evaluated at a common point, if and only if $\hat{\pi}_{j}^{i}$ is positive.

\footnotetext{
5 Similar results, though under less general assumptions, have been obtained by Dixit (1986) and Henriques (1990).
} 
This is so because the only justification for intervention by the union authority is to offset the failure of each individual firm to internalize the effects of its choice of investment on the profits of other firms.

Finally, to compare $\mu_{C}$ and $\mu_{N}$, we combine Eqs. (14) and (16), along with the firm's first-order condition (5), to derive the following expression, which is proportional to the difference between the cooperative and non-cooperative subsidies evaluated at any common point:

$$
\left(\mu_{C}-\mu_{N}\right) \theta x^{i}=(n-1) \hat{\pi}_{j}^{i}\left(1-\frac{\mathrm{d} k^{j}}{\mathrm{~d} k^{i}}\right)
$$

The term $1-\frac{\mathrm{d} k^{j}}{\mathrm{~d} k^{i}}$ is unambiguously positive from (19) and the Seade stability condition:

$$
1-\frac{\mathrm{d} k^{j}}{\mathrm{~d} k^{i}}=\frac{\hat{\Pi}_{j j}+(n-1) \hat{\Pi}_{j i}}{\hat{\Pi}_{j j}+(n-2) \hat{\Pi}_{j i}}>0
$$

This implies that an increase in investment by one firm cannot induce a greater reduction in investment by a rival firm. It follows from (21) that the criterion for the return to investment in the cooperative regime to exceed that in the non-cooperative one is the same as that in Proposition 2:

Proposition 3 When consumption is not valued $(\delta=0)$, the return to investment in the cooperative policy regime is higher than in the non-cooperative policy regime $\left(\mu_{C}>\mu_{N}\right)$, both evaluated at a common point, if and only if $\hat{\pi}_{j}^{i}$ is positive.

Thus cooperative setting of subsidies leads to higher returns to investment if and only if investment levels are friendly.

As already noted, the results so far are only local. To extend these to global comparisons, we have to make some mild additional assumptions, all but the first of which are taken from Leahy and Neary (1997). ${ }^{6}$ First, we assume that the rankings of the marginal returns to investment are the same in all three regimes. As Eqs. (17), (20), and (21) show, this merely requires that the two key criteria, whether or not investments are friendly (the sign of $\hat{\pi}_{j}^{i}$ ) and whether or not they are strategic substitutes (the sign of $\hat{\Pi}_{i j}$ ), are qualitatively invariant across all three regimes. In addition, we need to assume that appropriate stability conditions hold at all points along the path in the (one-dimensional) space of symmetric $\mathbf{k}$, which we denote by the scalar $\kappa$. Given these assumptions, it follows that, comparing symmetric equilibria, investment levels will be higher when the corresponding $\mu$ is higher. Formally:

Proposition 4 Assume that (a) the rankings of marginal returns to investment are the same in all three regimes; and (b) equilibrium is unique and stable (in the sense of Seade 1980) in all three stages of the game at each of the three regimes and at all intervening symmetric investment levels; then, the ranking of equilibrium investment

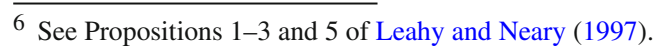


Table 1 Ranking of marginal returns to investment in different equilibria $(\delta=0)$

\begin{tabular}{llll}
\hline & & $\hat{\pi}_{j}^{i}$ & \\
\cline { 3 - 4 } & & - (Unfriendly) & + (Friendly) \\
\hline$\hat{\pi}_{i j}$ & - (Strategic substitutes) & (i) $\mu_{N}>\mu>\mu_{C}$ & (ii) $\mu_{C}>\mu>\mu_{N}$ \\
& + (Strategic complements) & (iii) $\mu>\mu_{N}>\mu_{C}$ & (iv) $\mu_{C}>\mu_{N}>\mu$ \\
\hline
\end{tabular}

levels across the three regimes is the same as the ranking of the marginal returns to investment.

The proof is the same as that of Proposition 5 in Leahy and Neary (1997) applied in turn to each bilateral comparison of the $\mu$ 's.

The next step is to show that the ranking of optimal subsidies across regimes is the same as the ranking of investment levels. This follows from the following Lemma:

Lemma 2 Comparing symmetric equilibria, an increase in subsidy levels is associated with an increase in investment levels.

Proof The proof follows immediately from the first-order condition for each firm's choice of investment level (5), written as a function of symmetric investment levels $\kappa$ and symmetric subsidies $\sigma$ :

$$
\hat{\Pi}_{k^{i}}(\kappa, \sigma)=0
$$

Totally differentiating this yields:

$$
\frac{\mathrm{d} \kappa}{\mathrm{d} \sigma}=-\frac{\hat{\Pi}_{k^{i} \sigma}}{\hat{\Pi}_{k^{i} \kappa}}=-\frac{1}{\hat{\Pi}_{i i}+(n-1) \hat{\Pi}_{i j}}>0
$$

The denominator must be negative from the Seade stability condition, so Lemma 2 follows immediately.

Assuming that the Seade condition holds at all points between any two equilibria to be compared, so Lemma 2 applies, we can deduce the sign of the optimal subsidies from the ranking of the $\mu$ 's. The implications of the three bilateral comparisons between marginal returns to investment given in Eqs. (17), (20) and (21) are summarized in Table $1 .^{7}$ Whether or not the union offers a higher subsidy than individual countries depends on the columns in Table 1: the union subsidy will be higher $\left(\mu_{C}>\mu_{N}\right)$ when

\footnotetext{
${ }^{7}$ In the two-firm case this table is reminiscent of the "animal spirits" taxonomy of Fudenberg and Tirole (1984), though since the derivatives are those of the reduced-form profit function $\hat{\pi}$ its interpretation is different. A better analogy is with the policy implications of the static export subsidy game of Brander and Spencer (1985): when firms' choice variables are strategic substitutes and friendly, so $\mu_{N}>\mu$, the nationally optimal policy is a subsidy; conversely, when firms' choice variables are strategic complements and friendly, so $\mu_{N}<\mu$, the nationally optimal policy is a tax.
} 
investment levels are friendly (the second column) and not otherwise. By contrast, whether or not individual governments provide positive or negative subsidies depends on whether the equilibrium falls in a diagonal or off-diagonal box: they will subsidize $\left(\mu_{N}>\mu\right)$ if the effects of one firm's investment on its rivals' profitability has the same sign in total as at the margin (i.e. along the diagonal of the table), otherwise they will tax. Note finally that there is no pattern which depends solely on the rows: whether or not investment levels are strategic substitutes does not pin down the relative ranking of any pair of marginal returns.

At this level of generality, not much can be said about the likelihood of the four different outcomes represented by the four boxes in Table 1. However, as noted in Leahy and Neary (2001) in a two-firm context, and as will emerge in the examples in Sects. 6 and 7, there is a presumption that the outcomes will fall in one of the diagonal boxes, at least in symmetric cases. Hence, to avoid excessive taxonomy, we concentrate in what follows on the diagonal boxes, numbered (i) and (iv): the outcomes in off-diagonal boxes can be deduced by analogy.

The final step is to deduce the rankings of welfare levels in the three regimes. Here the story is somewhat different, because welfare is not necessarily monotonic in symmetric investment levels. Given that competition between firms in the third stage is oligopolistic and that firms' outputs are not subsidized, the constrained optimal outcome for the union is when a cooperative investment subsidy or tax applies. Hence, union welfare, and by symmetry, national welfare, is maximized in the $C$ regime. Welfare in this regime is always (weakly) greater than welfare in either of the other two regimes. Bilateral comparisons between welfare in the other two regimes can only be made in the case where the $C$ regime is extremal. Fortunately, we can show that, subject to mild regularity conditions, in that case the ranking of marginal returns to investment corresponds to the ranking of welfare levels:

Proposition 5 When consumption is not valued $(\delta=0):(a)$ Welfare in the cooperative regime is always weakly higher than in the other two regimes; $(b)$ given $(i)$ the assumptions of Proposition 4, (ii) the additional assumption that, across symmetric equilibria, the welfare function $W$ is quasi-concave in $\kappa$, and (iii) $\mu_{C}$ is either greater or less than both $\mu$ and $\mu_{N}$; then, comparing the laissez-faire and non-cooperative regimes, the one with a return to investment closer to $\mu_{C}$ yields higher welfare.

Note, however, that when the $C$ regime is not extremal, we cannot rank the levels of welfare in the laissez-faire and non-cooperative regimes, though of course it is still true that they yield (weakly) lower welfare than in the cooperative regime.

Comparing welfare levels between the three regimes in cases where the cooperative regime is extremal corresponds to cases (i) and (iv) in Table 1. The centre and top panels of Fig. 1 illustrate these two cases respectively. In case (i), investment levels are inversely related to welfare across regimes, with the cooperative regime characterized by an investment tax. By contrast, investment levels are positively related to welfare across regimes in case (iv), with a higher subsidy mandated in the cooperative than in the noncooperative regime. Cases (ii) and (iii) are not illustrated but can easily be deduced, while case (v) can only arise when policy-makers take account of consumer welfare in setting their subsidies, the scenario to which we turn in the next section. 


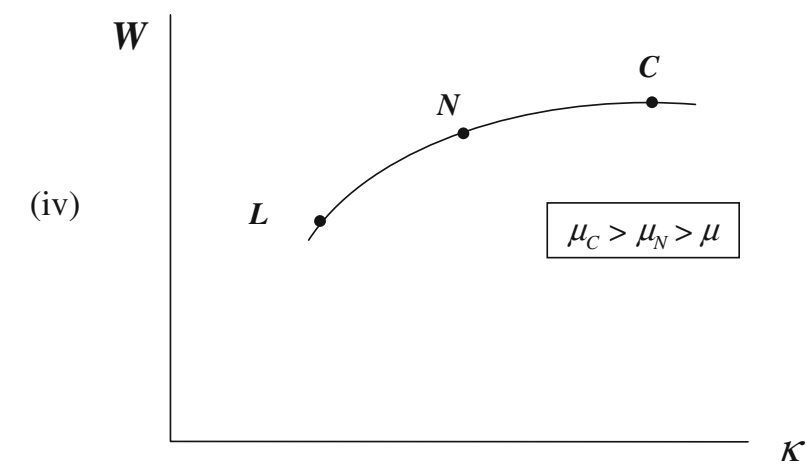

(i)
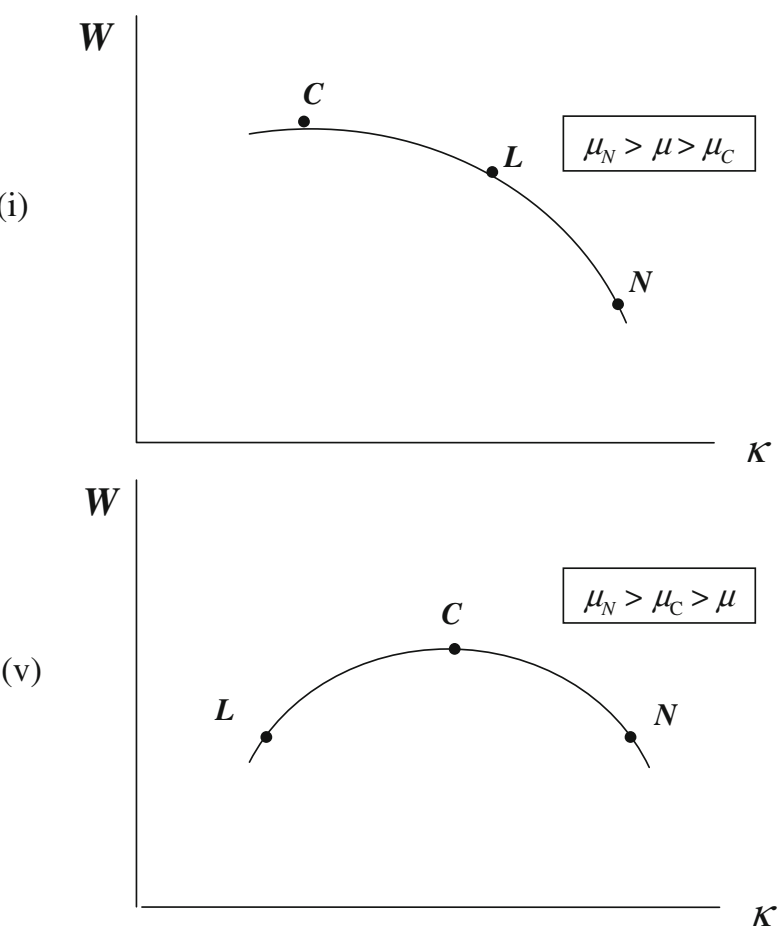

Fig. 1 Alternative welfare configurations

\section{Optimal policy when consumption is valued}

When some of the output is consumed within the bloc of countries and government policy respects consumer preferences, the previous derivations are altered in one key respect: whereas before "friendliness" was defined with respect to the effects of one firm's investment on the profits of another, it must now be redefined in terms of its effects on the welfare of another country. Differentiating the welfare function (8) yields: 


$$
\hat{W}_{j}^{i}=\hat{\pi}_{j}^{i}+\delta \hat{B}_{j}^{i}
$$

Clearly, profit-friendliness $\left(\hat{\pi}_{j}^{i}>0\right)$ contributes to welfare-friendliness $\left(\hat{W}_{j}^{i}>0\right)$, and the two criteria coincide in the export-only case $(\delta=0)$. However, we must also take account of what we can call "consumer-friendliness", i.e. whether the derivative $\hat{B}_{j}^{i}$ is positive or not.

We can be sure that investment is consumer-friendly, so $\hat{B}_{j}^{i}$ is positive, in one important special case, where investment does not affect preferences directly, so consumers are affected only indirectly via its effects on prices. In that case the benefit function for country $i$ takes the standard consumer surplus form:

$$
B^{i}=u^{i}\left(\mathbf{y}^{i}\right)-\sum_{h} p^{h} y^{h i}
$$

where $y^{h i}$ denotes the amount of country $h$ 's output consumed in country $i$. Differentiating with respect to the investment of country $j$ yields:

$$
\hat{B}_{j}^{i} \equiv \frac{\partial \hat{B}^{i}}{\partial k^{j}}=-\sum_{h} y^{h i} \frac{\mathrm{d} p^{h}}{\mathrm{~d} k^{j}}=-\frac{x}{n} \sum_{h} \frac{\mathrm{d} p^{h}}{\mathrm{~d} k^{j}}
$$

where we have imposed utility maximization $\left(u_{h}^{i}=p^{h}\right)$ and symmetry $\left(y^{h i}=x / n\right)$ to simplify. For a wide variety of models, investment lowers prices, and so, since consumers benefit from lower prices, the derivative of country $i$ 's consumer surplus with respect to the level of investment in country $j$ is positive. Note that, with symmetry, it is also independent of the country in which the investment occurs: $\hat{B}_{j}^{i}=\hat{B}_{i}^{i}>0$ for all $j$. For convenience we concentrate in the remainder of the text on this case, though the algebra is consistent with cases where investment affects utility directly and possibly with a negative sign.

To see the implications of this change in specification we once again need to compare the marginal returns to investment in the three regimes. That in the laissez-faire regime, $\mu$, arises from firm behaviour only. Hence it does not depend on consumer surplus and so its sign depends only on profit-friendliness as before. However, the signs of the other two depend on welfare-friendliness. In the noncooperative case the marginal return to investment per unit output is now defined implicitly by the following:

$$
\mu_{N} \theta x^{i}=\hat{W}_{i}^{i}+(n-1) \hat{W}_{j}^{i} \frac{\mathrm{d} k^{j}}{\mathrm{~d} k^{i}}
$$

while in the cooperative case it is defined by:

$$
\mu_{C} \theta x^{i}=\hat{W}_{i}^{i}+(n-1) \hat{W}_{i}^{j}
$$

Recalling (14) and (16), these differ from the case where $\delta$ is zero only in replacing profit derivatives with the corresponding welfare derivatives. 
As before, it is the comparisons between these marginal returns which matter for the relative rankings of subsidy levels and welfare. Consider first the difference between the marginal returns in the non-cooperative regime and in laissez-faire. This now becomes:

$$
\left(\mu_{N}-\mu\right) \theta x^{i}=\delta \hat{B}_{i}^{i}+(n-1) \hat{W}_{j}^{i} \frac{\mathrm{d} k^{j}}{\mathrm{~d} k^{i}}
$$

This can also be written as:

$$
\left(\mu_{N}-\mu\right) \theta x^{i}=\delta \hat{B}_{i}^{i} \frac{\mathrm{d} K}{\mathrm{~d} k^{i}}+(n-1) \hat{\pi}_{j}^{i} \frac{\mathrm{d} k^{j}}{\mathrm{~d} k^{i}}
$$

The first term is unambiguously positive, implying that a rise in one firm's investment cannot lower industry investment:

$$
\frac{\mathrm{d} K}{\mathrm{~d} k^{i}}=1+(n-1) \frac{\mathrm{d} k^{j}}{\mathrm{~d} k^{i}}=\frac{\hat{\Pi}_{j j}-\hat{\Pi}_{j i}}{\hat{\Pi}_{j j}+(n-2) \hat{\Pi}_{j i}}>0
$$

Both the numerator and denominator of this expression are negative under plausible restrictions: the former is the Hahn stability condition, while the latter as we have seen is implied by the Seade stability condition $\hat{\Pi}_{j j}+(n-1) \hat{\Pi}_{j i}<0$. As for the second term in (31), it is identical to that considered in the last section. (See Eq. 17.) Summarizing:

Proposition 6 When consumption is valued $(\delta>0)$, a sufficient but not necessary condition for the return to investment in the non-cooperative policy regime to be higher than in laissez-faire $\left(\mu_{N}>\mu\right)$, both evaluated at a common point, is that $\hat{\pi}_{j}^{i}$ and $\hat{\Pi}_{i j}$ have the same sign.

Hence (recalling Proposition 1) we can conclude that the return to investment in the non-cooperative policy regime is more likely to exceed that in laissez-faire when consumption is valued than when it is not, since national-welfare-maximizing governments are more likely to offer a subsidy even if firms over-invest for strategic reasons.

Next, the comparison between $\mu_{C}$ and $\mu$ is more complex than in the last section. It is given by:

$$
\left(\mu_{C}-\mu\right) \theta x^{i}=\delta \hat{B}_{i}^{i}+(n-1) \hat{W}_{j}^{i}
$$

Now welfare-friendliness is sufficient for $\mu_{C}$ to be greater than $\mu$, but it is not necessary. This condition can be strengthened by making use of the symmetry of the consumerfriendliness term (so $\hat{B}_{j}^{i}=\hat{B}_{i}^{i}$ ) to rewrite (33) as follows, :

$$
\left(\mu_{C}-\mu\right) \theta x^{i}=(n-1) \hat{\pi}_{j}^{i}+\delta n \hat{B}_{i}^{i}
$$


Table 2 Ranking of marginal returns to investment in different equilibria $(\delta>0)$

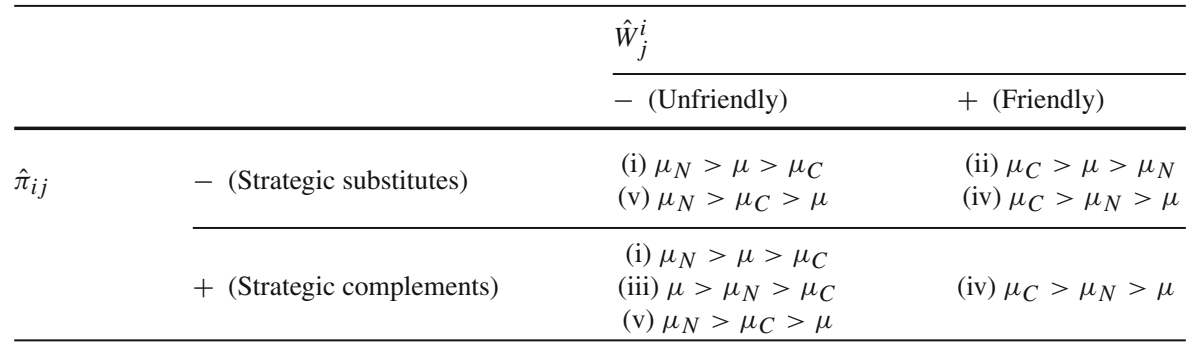

This shows that profit-friendliness is sufficient for a positive subsidy by the union, but even if investments are profit-unfriendly a subsidy may still be justified by a sufficiently high degree of consumer-friendliness. Summarizing:

Proposition 7 When consumption is valued $(\delta>0)$, a sufficient but not necessary condition for the return to investment in the cooperative policy regime to exceed that in laissez-faire $\left(\mu_{C}>\mu\right)$, both evaluated at a common point, is that $\hat{\pi}_{j}^{i}$ is positive.

Finally, compare $\mu_{C}$ and $\mu_{N}$. The difference between them can be written as follows:

$$
\left(\mu_{C}-\mu_{N}\right) \theta x^{i}=(n-1) \hat{W}_{j}^{i}\left(1-\frac{\mathrm{d} k^{j}}{\mathrm{~d} k^{i}}\right)
$$

The expression in parentheses is positive as we saw in the last section. (See Eq. 22.) Hence the sign of the right-hand side depends only on welfare-friendliness: cooperation mandates higher levels of investment if and only if each country's welfare is enhanced by higher investment in other countries.

Proposition 8 When consumption is valued $(\delta>0)$, the return to investment in the cooperative policy regime is higher than in the non-cooperative policy regime $\left(\mu_{C}>\mu_{N}\right)$, both evaluated at a common point, if and only if $\hat{W}_{j}^{i}$ is positive.

Comparing Proposition 3, we can see that attaching a weight to consumption leads to welfare-friendliness taking over the role played by profit-friendliness in the profitshifting case.

The implications of these comparisons are summarized in Table 2, where the columns reflect whether investments are welfare-friendly or unfriendly. The range of possibilities is greater than in the case of $\delta=0$ considered in the previous section. (Compare Table 1.) Now it matters whether investment levels are friendly from the perspective of welfare as well as from that of profits. We have assumed that they are always consumer-friendly, so if investment levels are profit-friendly they must also be welfare-friendly. However, if they are profit-unfriendly they can be either welfarefriendly or unfriendly. Hence there are more possibilities in the off-diagonal cells of the table. In addition, a fifth regime is possible when investments are welfare-unfriendly: national governments may over-subsidize from the union's point of view even though 
the laissez-faire regime implies under-subsidization. ${ }^{8}$ This case is illustrated in the final panel of Fig. 1, where we continue to concentrate on the cases in the diagonal cells of the table.

Finally, these comparisons between the marginal cost of investment in the different regimes translate into comparisons between welfare subject to the same qualifications as in Propositions 4 and 5 in the last section.

\section{The linear-quadratic Cournot case}

So far we have presented our results in terms of a very general view of the two types of investment links between firms: whether higher investment by one firm raises rival firms' profits or rival countries' welfare in total (friendliness) and at the margin (strategic substitutability). To show how these concepts can be applied, it is helpful to look more closely at some important special cases which also allow us to derive closed-form solutions and to calculate explicitly the marginal return to investment under different assumptions about policy setting. In this section we consider the case of investment in cost-reducing $\mathrm{R} \& \mathrm{D}$ followed by Cournot competition with differentiated products, under the assumptions of linear demand and quadratic costs of investment.

Under these assumptions the specification of technology and demands is as follows. The R\&D cost function is $\Gamma\left(k^{i}\right)=\frac{1}{2} \gamma\left(k^{i}\right)^{2}$, where $\gamma$ is a positive constant, so $\Gamma^{\prime}\left(k^{i}\right)=\gamma k^{i}$. As for marginal production costs, they fall linearly in R\&D:

$$
c^{i}=c_{0}-\theta\left\{(1-\beta) k^{i}+\beta K\right\}, \quad 0 \leq \beta \leq 1,
$$

where $K \equiv \Sigma_{i} k^{i}$ is industry $\mathrm{R} \& \mathrm{D}, c_{0}$ and $\theta$ are positive constants, and $\beta$ denotes the spillover coefficient which is also constant. Hence the marginal production cost of any firm depends inversely on a weighted average of its own investment and of aggregate industry investment, where the weights depend on $\beta$. As for the inverse demand curve facing firm $i$, it is linear in outputs:

$$
p^{i}=a-b\left\{(1-e) x^{i}+e X\right\}, \quad 0 \leq e \leq 1 .
$$

Here $a, b$ and $e$ are positive constants, with $e$ an inverse measure of product differentiation, and $X \equiv \Sigma_{i} x^{i}$ is industry output. This demand function implies that the price which consumers are willing to pay for any good depends inversely on a weighted average of its own output and of the output of all goods, where the weights depend on $e$.

The first-order condition for output in the final stage of the game is:

$$
\frac{\partial \pi^{i}}{\partial x^{i}}=p^{i}-c^{i}-b x^{i}=a-b\left\{(2-e) x^{i}+e X\right\}-c^{i}=0
$$

\footnotetext{
8 The remaining possibility, case (vi), with $\mu>\mu_{C}>\mu_{N}$, cannot arise when investment is consumerfriendly, i.e. when $\hat{B}_{j}^{i}$ is positive.
} 
Summing over $i$, we can solve for industry output and then substitute back into (38) to solve for firm output:

$$
X=\frac{n a-\Sigma c^{j}}{b E} \quad x^{i}=\frac{E\left(a-c^{i}\right)-e\left(n a-\Sigma c^{j}\right)}{b(2-e) E}
$$

where $E \equiv 2+(n-1) e>0$. Equation (36) gives an explicit expression for $c^{i}$, which also implies that $\Sigma c^{j}$ equals $n c_{0}-\mu_{O} \theta K$, where $\mu_{O} \equiv 1+(n-1) \beta$ is the marginal social return to R\&D. Substituting for these into (39), the levels of industry and firm output can be written as functions of the levels of industry and firm R\&D:

$$
\begin{aligned}
X & =\frac{1}{b E}\left[n\left(a-c_{0}\right)+\mu_{O} \theta K\right] \\
x^{i} & =\frac{1}{b(2-e)}\left[\frac{2-e}{E}\left(a-c_{0}\right)+(1-\beta) \theta k^{i}+\frac{2 \beta-e}{E} \theta K\right]
\end{aligned}
$$

The coefficient of $K$ in (41) gives the cross-effect of one firm's investment in R\&D on another's output:

$$
\frac{\partial x^{i}}{\partial k^{j}}=\frac{2 \beta-e}{b(2-e) E} \theta
$$

Thus $\mathrm{R} \& \mathrm{D}$ reduces rival output for zero or low spillovers (i.e. $\beta<\frac{e}{2}$ ), but increases it if spillovers are large and/or product differentiation is low (i.e. $\beta>\frac{e}{2}$ ). As for the own-effect of investment on output, it is given by the sum of the coefficients of $k^{i}$ and $K$, and is always positive:

$$
\frac{\partial x^{i}}{\partial k^{i}}=\frac{(1-\beta) E+2 \beta-e}{b(2-e) E} \theta=\left[1+\frac{(n-1) e}{(2-e) E}(e-2 \beta)\right] \frac{\theta}{2 b}>0
$$

We now have all the building blocks we need to derive the criteria for profit friendliness and strategic substitutability in this model. Note first from (38) that profits (in the absence of subsidies) can be written as:

$$
\Pi^{i}=\left(p^{i}-c^{i}\right) x^{i}-\gamma\left(k^{i}\right)^{2} / 2=b\left(x^{i}\right)^{2}-\gamma\left(k^{i}\right)^{2} / 2
$$

Hence the criterion for profit friendliness is the same as that for $R \& D$ to raise rival output from (42):

$$
\hat{\pi}_{j}^{i}=2 b x^{i} \frac{\partial x^{i}}{\partial k^{j}}=2 \frac{2 \beta-e}{(2-e) E} \theta x^{i}
$$

Similarly, using (43), the private marginal return to R\&D is given by:

$$
\hat{\pi}_{i}^{i}=2 b x^{i} \frac{\partial x^{i}}{\partial k^{i}}=\mu \theta x^{i} \quad \text { where: } \quad \mu=1+\frac{(n-1) e}{(2-e) E}(e-2 \beta)
$$


This shows that firms have an incentive to over-invest relative to the non-strategic benchmark (i.e. $\mu>1$ ) only when $\beta$ is less than $\frac{e}{2}$. Finally, differentiating (46) with respect to $k^{j}$ gives the criterion for strategic substitutability:

$$
\hat{\pi}_{i j}=\mu \theta \frac{\partial x^{i}}{\partial k^{j}}=\mu \eta \frac{2 \beta-e}{(2-e) E} \gamma
$$

where $\eta \equiv \theta^{2} / b \gamma$ is a measure of the relative effectiveness of R\&D. Once again, we see that the sign of this depends solely on $2 \beta-e$. Hence, just as in the two-firm case of Leahy and Neary (2001), the criteria for strategic complementarity and profit friendliness are identical: both require that $\beta$ exceed $\frac{e}{2}$.

We can now fully characterize the possible outcomes in the case where consumption is not valued $(\delta=0)$. Because the criteria for strategic complementarity and profit friendliness coincide, only the diagonal cells in Table 1 apply, so the only possible cases are (i) and (iv). ${ }^{9}$ Moreover, from (17), national governments always offer positive subsidies to R\&D: the return to R\&D in the national optimum, $\mu_{N}$, is always greater than that in free trade, $\mu$. Which of these two cases is closer to the global optimum for the union depends on whether investments are friendly (or, equivalently, whether they are strategic complements). Case (i) applies when investments are unfriendly, which in this model implies that either spillovers are low or competition is intense because products are relatively undifferentiated (so $\beta$ is less than $\frac{e}{2}$ ). It is illustrated in panel (i) of Fig. 1. In this case the national optimum leads to over-subsidization. A commitment to laissez-faire would be superior to this, though still leading to more investment than the global optimum. By contrast, case (iv) applies when investments are friendly, either because spillovers are high or because products are relatively more differentiated and so competition is less intense ( $\beta$ is greater than $\frac{e}{2}$ ), and it is illustrated in panel (iv) of Fig. 1. Now laissez-faire is the worst outcome. Non-cooperative subsidy-setting by national governments yields higher R\&D and welfare, though less than the globally optimal levels.

The two regimes are illustrated from a different perspective in Fig. 2, drawn in the space of $\beta$ and $e$. When consumption is not valued, the dashed locus $\beta=\frac{e}{2}$ corresponds to the case where all three marginal returns to investment are equal: $\mu_{C}=\mu_{N}=\mu$. Hence it divides the space into two regions corresponding to cases (iv) and (i) (above and below the locus, respectively).

When consumption is valued, the discussion so far must be augmented by taking account of whether investment is consumer-friendly, and (in conjunction with profits) welfare-friendly. Given our linear demand specification, the general expression for consumer-friendliness in (27) becomes:

$$
\hat{B}_{j}^{i}=\hat{B}_{i}^{i}=-\frac{x}{n} \sum_{h} \frac{\mathrm{d} p^{h}}{\mathrm{~d} k^{i}}=-\frac{x}{n} \frac{\mathrm{d} P}{\mathrm{~d} k^{i}}
$$

\footnotetext{
9 There is also a borderline case where all three equilibria coincide, when $\beta$ and $\frac{e}{2}$ are equal. To avoid tedious repetition we ignore such borderline cases in the text: their properties can easily be deduced by combining those of their two neighbouring regimes.
} 


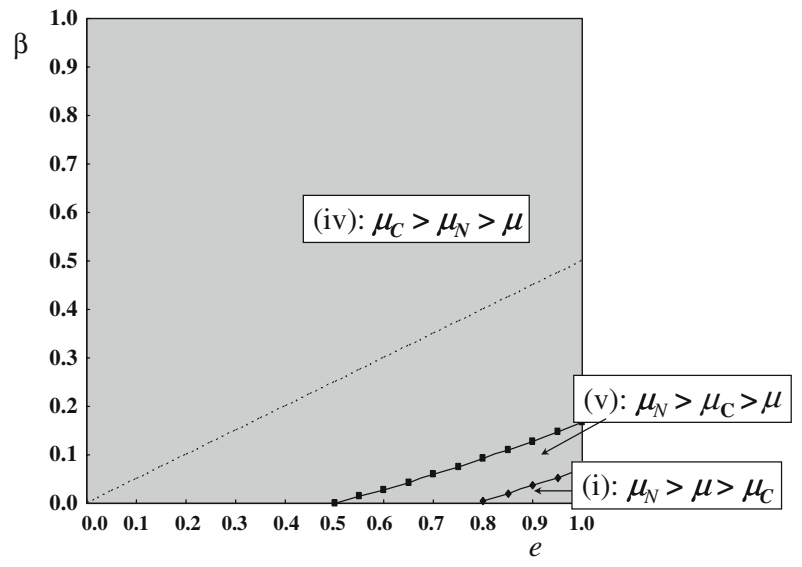

Fig. 2 Ranking of marginal returns to R\&D in Cournot competition, $n=3, \delta=0$ (dashed locus) and $\delta=1$ (solid loci)

where we use $P$ to denote the sum of prices: $P \equiv \Sigma_{j} p^{j}=n a-b\{1+(n-1) e\} X=$ $n a-b(E-1) X$. Differentiating this with respect to $k^{i}$ and using Eq. (40) to eliminate the effect of one firm's investment on industry output yields:

$$
\hat{B}_{i}^{i}=-\frac{x}{n} \frac{\mathrm{d} P}{\mathrm{~d} k^{i}}=\frac{x}{n} b(E-1) \frac{\mathrm{d} X}{\mathrm{~d} k^{i}}=\frac{x}{n}(E-1) \frac{\theta \mu_{O}}{E}
$$

So, investment is always consumer-friendly in this model.

Consider now the implications of the value of $\hat{B}_{i}^{i}$ for the ranking of the different marginal returns to R\&D. From (31) it is clear that $\mu_{N}$ always exceeds $\mu$ : as already noted, the fact that investment is consumer-friendly gives an additional motive for national governments to subsidize $\mathrm{R} \& \mathrm{D}$, and this reinforces the fact that the "profitshifting" motive always mandates a positive subsidy in the linear-quadratic Cournot case. Hence only regimes (i), (iv) and (v) in Table 2 can prevail in this case. It is also clear from (35) that $\mu_{C}$ exceeds $\mu_{N}$ if and only if investments are welfare-friendly. Substituting from (45) and (49) for profit- and consumer-friendliness, respectively, the condition for welfare-friendliness becomes:

$$
\hat{W}_{j}^{i}=\hat{\pi}_{j}^{i}+\delta \hat{B}_{j}^{i}=\frac{1}{E}\left[\frac{2}{2-e}(2 \beta-e)+\delta(E-1) \mu_{O} \frac{1}{n}\right] \theta x
$$

Eliminating $\mu_{0}$, the threshold value of $\beta$ for investment to be welfare-friendly and hence for $\mu_{C}$ to exceed $\mu_{N}$ becomes:

$$
\mu_{C}>\mu_{N} \Leftrightarrow \beta>\frac{e-\delta(E-1) \frac{2-e}{2} \frac{1}{n}}{2+\delta(E-1) \frac{2-e}{2} \frac{n-1}{n}}
$$

Clearly the threshold value of $\beta$ reduces to $\frac{e}{2}$ when consumption is not valued $(\delta=0)$, and it is decreasing in $\delta$. In the relevant range, $\delta \in(0,1]$ and $e \in[0,1]$, the threshold 
is negative for low $e$ and positive for high $e$, rising monotonically from $-\frac{\delta}{2 n+(n-1) \delta}$ when $e$ equals zero to attain its maximum value (given $\delta$ ) of $\frac{2-\delta}{4+(n-1) \delta}$ when $e$ equals one. It is illustrated by the solid boundary between regimes (iv) and (v) in Fig. 2 for the special case of $\delta=1$, when the end-points simplify to $-\frac{1}{3 n-1}$ at $e=0$ and $\frac{1}{n+3}$ at $e=1$. Hence we can conclude that national governments over-subsidize only for relatively low spillovers or relatively high degrees of competition (in the sense of high values of $e$ ).

Unlike the case where consumption is not valued, a coincidence between the two subsidy regimes does not imply that they coincide with laissez-faire, so there is a non-empty region $(\mathrm{v})$ where national governments over-subsidize $\left(\mu_{C}<\mu_{N}\right)$ but laissez-faire yields too little $\mathrm{R} \& \mathrm{D}\left(\mu_{C}>\mu\right)$. The boundary between this region and region (i) corresponds to the threshold value of $\beta$ which equates $\mu_{C}$ and $\mu$. From (33), the difference between $\mu_{C}$ and $\mu$ depends on $(n-1) \hat{\pi}_{j}^{i}+\delta n \hat{B}_{i}^{i}$, which, again substituting from (45) and (49), becomes:

$$
(n-1) \hat{\pi}_{j}^{i}+\delta n \hat{B}_{i}^{i}=\frac{1}{E}\left[\frac{2}{2-e}(n-1)(2 \beta-e)+\delta(E-1) \mu_{O}\right] \theta x
$$

Eliminating $\mu_{0}$ once again, the threshold value of $\beta$ for $\mu_{C}$ to exceed $\mu$ becomes:

$$
\mu_{C}>\mu \Leftrightarrow \beta>\frac{e-\delta(E-1) \frac{2-e}{2} \frac{1}{n-1}}{2+\delta(E-1) \frac{2-e}{2}}
$$

It is clear by inspection that this is qualitatively similar to (51), the threshold value of $\beta$ which equates the marginal returns to $\mathrm{R} \& \mathrm{D}$ in the national and cooperative regimes. It also reduces to $\frac{e}{2}$ when consumption is not valued $(\delta=0)$, it is decreasing in $\delta$ and increasing in $e$. Furthermore, it is always lower than the threshold value in (51). This can be seen by comparing the general expressions (35) and (33): the former shows that national governments and the union as a whole have identical incentives to intervene when investment is welfare-neutral, $\hat{W}_{j}^{i}$ is zero; but the latter shows that in this case the union still has a motive to provide a positive subsidy provided investment is strictly consumer friendly, $\hat{B}_{j}^{i}>0$. The implications of this are shown in Fig. 2, where the threshold in (53) is illustrated by the solid boundary between regimes (v) and (i) for the special case of $\delta=1$, when the end-points simplify to $-\frac{1}{3(n-1)}$ at $e=0$ and $\frac{n-2}{(n-1)(n+4)}$ at $e=1 .{ }^{10}$ Clearly the emergence of regime (v) almost completely eliminates regime (i) relative to the case where $\delta$ is zero (when it prevails in the whole of the area below the dashed line $\beta=\frac{e}{2}$ ). Only when goods are near-perfect substitutes, so competition is very intense, and spillovers are close to zero, is it optimal for the union to tax R\&D, even though individual governments have an incentive to subsidize it.

10 For $e=\delta=1$, the threshold value of $\beta$ rises from zero at $n=2$ to a maximum of $\frac{1}{12}$ or 0.0833 at $n=4$ and 5 , and then falls. 


\section{The linear-quadratic Bertrand case}

The second special case we consider in more detail retains the cost assumptions of the previous section but assumes that firms compete by setting prices rather than quantities. It is now more convenient to write the demand functions in direct rather than inverse form:

$$
x^{i}=\alpha-\phi\left\{(1+\varepsilon) p^{i}-\varepsilon P\right\}
$$

where $P \equiv \Sigma_{j} p^{j}$ denotes the sum of all prices as in the last section. It is clear by inspection that the substitution parameter $\varepsilon$ must be less than $\frac{1}{n-1}$ in a symmetric equilibrium. We can go further if we assume that the direct demands in (54) are derived from the same individual utility function as the inverse demands (37) in the previous section: it then follows that $\varepsilon$ is directly related to the primitive substitution parameter $e: \varepsilon \equiv \frac{e}{1+(n-2) e} \cdot 11$

We can now proceed in a similar series of steps to those in the previous section. The first-order condition for price in the final stage of the game is:

$$
\frac{\partial \pi^{i}}{\partial p^{i}}=x^{i}-\phi\left(p^{i}-c^{i}\right)=\alpha-\phi\left\{(2+\varepsilon) p^{i}-\varepsilon P\right\}+\phi c^{i}=0
$$

Summing over $i$, we can solve for the sum of prices and then substitute back to solve for individual prices:

$$
P=\frac{n \alpha+\phi \Sigma c^{j}}{\phi E^{\prime}} \quad p^{i}=\frac{\alpha+\phi\left(c^{i}+\varepsilon P\right)}{\phi(2+\varepsilon)}
$$

where $E^{\prime} \equiv 2-(n-1) \varepsilon>0$. Combining with the demand function we can then solve for firm output:

$$
x^{i}=\frac{\alpha+\phi \varepsilon P-(1+\varepsilon) \phi c^{i}}{2+\varepsilon}
$$

Differentiating this we can calculate the crucial cross-effect of one firm's R\&D on a rival firm's output:

$$
\frac{\partial x^{i}}{\partial k^{j}}=\frac{\phi}{2+\varepsilon}\left[\varepsilon \frac{\partial P}{\partial k^{j}}-(1+\varepsilon) \frac{\partial c^{i}}{\partial k^{j}}\right]=\frac{\phi \theta}{(2+\varepsilon) E^{\prime}}\left[(1+\varepsilon) E^{\prime} \beta-\varepsilon \mu_{0}\right]
$$

\footnotetext{
11 See Neary (2002) for a full demonstration. The underlying utility function is quadratic, and the parameters $\alpha$ and $\phi$ are also related to the primitive parameters $a, b$ and $e: \alpha \equiv a /[b\{1+(n-1) e\}]$ and $\phi \equiv \alpha[1+(n-2) e] /[a(1-e)]$. We rule out the case where $e$ equals one, so goods are perfect substitutes, since the inverse demand functions cannot be inverted. This also serves to avoid the case where no equilibrium in pure strategies exists.
} 
Substituting for $\mu_{0} \equiv 1+(n-1) \beta$, the condition for this to be positive is:

$$
\frac{\partial x^{i}}{\partial k^{j}}>0 \Leftrightarrow \beta>\frac{\varepsilon}{(1+\varepsilon) E^{\prime}-(n-1) \varepsilon}
$$

This is easier to relate to the results of the last section when we reexpress $\varepsilon$ in terms of the primitive substitution parameter $e$ :

$$
\frac{\partial x^{i}}{\partial k^{j}}>0 \Leftrightarrow \beta>\frac{\{1+(n-2) e\} e}{2+2(n-2) e-(n-1) e^{2}}
$$

The importance of this expression is that, just as in the last section, it is also the criterion for investments to be both profit-friendly and strategic complements. This can be seen immediately by differentiating operating profits $\hat{\pi}$ which equal $\phi^{-1}\left(x^{i}\right)^{2}$ :

$$
\hat{\pi}_{j}^{i}=2 \frac{x^{i}}{\phi} \frac{\partial x^{i}}{\partial k^{j}} \text { and } \hat{\pi}_{i j}=\frac{\partial \hat{\pi}_{j}^{i}}{\partial k^{i}}=\frac{2}{\phi} \frac{\partial x^{i}}{\partial k^{j}} \frac{\partial x^{i}}{\partial k^{i}}
$$

To prove the required result it only remains to show that $\partial x^{i} / \partial k^{i}$ is positive. Differentiating the expression for $x^{i}$ with respect to $k^{i}$ :

$$
\frac{\partial x^{i}}{\partial k^{i}}=\frac{\phi}{2+\varepsilon}\left[\varepsilon \frac{\partial P}{\partial k^{i}}-(1+\varepsilon) \frac{\partial c^{i}}{\partial k^{i}}\right]=\frac{\phi \theta}{(2+\varepsilon) E^{\prime}}\left[(1+\varepsilon) E^{\prime}-\varepsilon \mu_{0}\right]
$$

Now rewrite the final term in square brackets using $\mu_{0} \equiv 1+(n-1) \beta=$ $n-(n-1)(1-\beta)$ :

$$
(1+\varepsilon) E^{\prime}-\varepsilon \mu_{0}=(2+\varepsilon)[1-(n-1) \varepsilon]+\varepsilon(n-1)(1-\beta)
$$

The first term on the right-hand side is strictly positive, and so the same must be true of $\partial x^{i} / \partial k^{i}$. Hence we can conclude that the criteria for profit-friendliness and strategic complementarity coincide, just as in the Cournot case of Sect. 6.

This threshold value of $\beta$ for profit-friendliness and strategic complementarity is illustrated in Fig. 3 for the cases of $n$ equal to 2 and 15. The results for the Bertrand export-only case differ quantitatively from those for the Cournot case of the last section, where the threshold value for $\beta$ was simply $\frac{e}{2} .{ }^{12}$ Notwithstanding the fact that firm's actions (i.e. prices) are now strategic complements, the range of parameters for which $\mathrm{R} \& \mathrm{D}$ levels are strategic complements is smaller. Another difference is that the number of firms now affects the threshold, unlike in the Cournot case, though not at the endpoints (the threshold equals zero at $e=0$ and one at $e=1$, for all values of $n$ ), and, in practice, the effect of changes in the number of firms is small as the figure shows.

\footnotetext{
12 The differences between the two can be seen more clearly by rewriting the threshold value of $\beta$ in (60) as $e\left[2-\frac{(n-1) e^{2}}{1+(n-2) e}\right]^{-1}$, showing that it equals $\frac{e}{2}$ except for the final term in the denominator, $-(n-1) e^{2}$.
} 


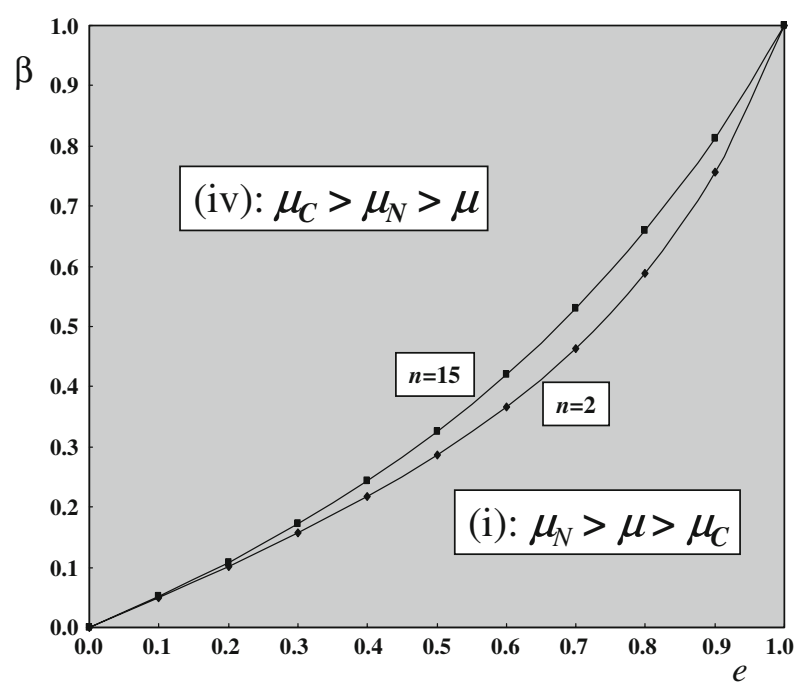

Fig. 3 Ranking of marginal returns to R\&D in Bertrand competition, $n=2$ and 15, $\delta=0$

Overall, the conclusions are qualitatively identical to the Cournot case. As before, the threshold $\beta$ is increasing in $e$ and only the diagonal entries in Table 1 apply. Low values of $\beta$ and high values of $e$ imply that $\mathrm{R} \& \mathrm{D}$ levels are unfriendly and strategic substitutes, and therefore that regime (i) obtains: non-cooperation leads to excessive investment, and banning subsidies would improve welfare. Conversely, high values of $\beta$ imply that regime (iv) obtains: non-cooperative subsidy-setting leads to too little investment and reduces welfare below the (constrained) welfare-maximizing level, but banning subsidies would be even worse. Finally, these results can be extended to take account of consumption being valued $(\delta>0)$, but as in the previous section this serves mainly to expand the range of parameter values corresponding to regime (iv).

\section{Conclusion}

This paper has considered the rationale for multilateral agreements to limit investment subsidies. We presented a general multi-firm model of investment competition between oligopolistic firms, and provided a welfare ranking for different symmetric international industrial policy games.

Our general model identifies three key factors which influence the desirability of national assistance to investment. Two of these relate to the effects of one firm's investment on its rivals' profits: does it raise rivals' profits in total, so investment levels are "friendly"?; and does it raise them at the margin, so investment levels are "strategic complements"? The third factor is the importance which policy makers attach to domestic consumption of the subsidized industry's output relative to the profits of domestic producers.

In the benchmark case when consumption is not valued, the range of outcomes is fairly restricted, and reflects the insights from the literature on strategic trade policy, 
though here extended to a more general context. If investments are unfriendly and strategic substitutes, our results show that national-welfare maximizing governments will over-subsidize investment for rent-shifting reasons. Hence an enforced ban on subsidies would improve welfare, though optimal intervention would require taxing it to curb the tendency of firms to over-invest for strategic reasons. By contrast, when investments are friendly and strategic complements, national governments do not subsidize enough from the point of view of union welfare, although intervention is better than nothing, in that welfare is higher than with non-intervention.

When the industry's output is partly or wholly consumed within the union, and policy makers respect consumer preferences, the range of outcomes is greater, but there is a stronger presumption that subsidies are socially desirable. Even if investments are profit-unfriendly, so one firm's investment reduces its rivals' incentives to invest, it may still be welfare-improving to subsidize it if it is sufficiently consumer-friendly. In this case the investment subsidy serves as a partial proxy for an output subsidy which would offset the oligopoly distortion and raise consumption towards the socially desirable level.

We also considered in more detail the special case of R\&D competition followed by either Cournot or Bertrand competition with linear-quadratic functional forms. Here the general criteria of investment friendliness and strategic substitutability turn out to hinge on the magnitude of $R \& D$ spillovers and on the intensity of competition between firms, as measured by the degree of product substitutability. Low spillovers and/or more intense competition because products are very close substitutes imply that R\&D levels are unfriendly and strategic substitutes. In that case, non-cooperation leads to excessive investment, and banning subsidies would improve welfare. Conversely, high spillovers and/or less intense competition because products are relatively more differentiated imply that R\&D levels are friendly and strategic complements. In that case non-cooperative subsidy-setting leads to too little investment and reduces welfare below the (constrained) welfare-maximizing level, but banning subsidies would be even worse. A feature of these findings is that the Cournot and Bertrand cases yield qualitatively identical results, especially when we interpret the substitution parameter correctly.

Our results can be used to assess the benefits of multilateral agreements to limit national aid to firms in an imperfectly competitive setting. The model can also be applied to the issue of state assistance to industry in a federal setting. As we have noted, for example the European Commission, though it is opposed to national state aid to firms in general, tends to take a much more lenient view of R\&D subsidies than it does of production subsidies. Our model allows us to assess the economic rationale for this. ${ }^{13}$

\footnotetext{
13 Of course, a complete cost-benefit analysis of appropriate policies should consider other issues as well, including the social cost of financing subsidies, the potential for patent policy to make spillovers appropriable, and the desirability of permitting research joint ventures to encourage information-sharing. See Spence (1984) for an introduction to some of these issues.
} 
Open Access This article is distributed under the terms of the Creative Commons Attribution Noncommercial License which permits any noncommercial use, distribution, and reproduction in any medium, provided the original author(s) and source are credited.

\section{References}

Bagwell, K., Staiger, R.W.: The sensitivity of strategic and corrective R\&D policy in oligopolistic industries. J Int Econ 36, 133-150 (1994)

Besley, T., Seabright, T.: The effects and policy implications of state aids to industry: an economic analysis. Econ Policy 28, 14-53 (1999)

Brander, J.A: Strategic trade policy. In: Grossman, G., Rogoff, K. (eds.) Handbook of International Economics. vol. 3., pp. 1395-1455. Amsterdam: North-Holland (1995)

Brander, J.A., Spencer, B.J.: Export subsidies and international market share rivalry. J Int Econ 18, 83-100 (1985)

Collie, D.R.: State aid in the European union: the prohibition of subsidies in an integrated market. Int J Ind Organ 18, 867-884 (2000)

Collie, D.R.: Prohibiting state aid in an integrated market: Cournot and Bertrand oligopolies with differentiated products. J Ind Compet Trade 2, 215-231 (2002)

Collie, D.R.: State aid to investment and R\&D. European Economy Economic Papers, No. 231, European Commission, Brussels (2005)

Commission of the European Communities: State Aid Action Plan: Less and Better Targeted State Aid: A Roadmap for State Aid Reform 2005-2009, Brussels (2005)

Dixit, A.: Comparative statics for oligopoly. Int Econ Rev 27, 107-122 (1986)

Fudenberg, D., Tirole, J.: The fat-cat effect, the puppy-dog ploy, and the lean and hungry look. Am Econ Rev Pap Proc 74, 361-366 (1984)

Haaland, J.I., Kind, H.J.: Cooperative and non-cooperative R\&D policy in an economic union. Rev World Econ 142, 720-745 (2006)

Haaland, J.I., Kind, H.J.: R\&D policies, trade and process innovation. J Int Econ 74, 170-187 (2008)

Henriques, I.: Cooperative and noncooperative R\&D in duopoly with spillovers: Comment. Am Econ Rev 80, 638-640 (1990)

Kreps, D.M., Scheinkman, J.A.: Quantity precommitment and Bertrand competition yield Cournot outcomes. Bell J Econ 14, 326-337 (1983)

Leahy, D., Neary, J.P.: Public policy towards R\&D in oligopolistic industries. Am Econ Rev 87, 642-662 (1997)

Leahy, D., Neary, J.P.: Robust rules for industrial policy in open economies. J Int Trade Econ Dev 10, 393-409 (2001)

Maggi, G.: Strategic trade policies with endogenous mode of competition. Am Econ Rev 86, 237-258 (1996)

Neary, J.P.: Foreign competition and wage inequality. Rev Int Econ 10, 680-693 (2002)

Neary, J.P., Leahy, D.: Strategic trade and industrial policy towards dynamic oligopolies. Econ J 110, 484-508 (2000)

Seade, J.: The stability of Cournot revisited. J Econ Theory 23, 15-27 (1980)

Spence, M.: Cost reduction, competition, and industry performance. Econometrica 52, 101-121 (1984)

Spencer, B.J., Brander, J.A.: International R\&D rivalry and industrial strategy. Rev Econ Stud 50, $707-722$ (1983) 